\title{
Efficacy, safety, quality control, marketing and regulatory guidelines for herbal medicines (phytotherapeutic agents)
}

\section{J.B. Calixto}

\section{Correspondence}

\section{J.B. Calixto}

Departamento de Farmacologia, UFSC

88015-420 Florianópolis, SC Brasil

Fax: + 55-48-222-4164

E-mail: calixto@ farmaco.ufsc.br

Received November 3, 1999

Accepted November 29, 1999
Departamento de Farmacologia, Universidade Federal de Santa Catarina, Florianópolis, SC, Brasil

\section{Abstract}

This review highlights the current advances in knowledge about the safety, efficacy, quality control, marketing and regulatory aspects of botanical medicines. Phytotherapeutic agents are standardized herbal preparations consisting of complex mixtures of one or more plants which contain as active ingredients plant parts or plant material in the crude or processed state. A marked growth in the worldwide phytotherapeutic market has occurred over the last 15 years. For the European and USA markets alone, this will reach about $\$ 7$ billion and $\$ 5$ billion per annum, respectively, in 1999, and has thus attracted the interest of most large pharmaceutical companies. Insufficient data exist for most plants to guarantee their quality, efficacy and safety. The idea that herbal drugs are safe and free from side effects is false. Plants contain hundreds of constituents and some of them are very toxic, such as the most cytotoxic anti-cancer plant-derived drugs, digitalis and the pyrrolizidine alkaloids, etc. However, the adverse effects of phytotherapeutic agents are less frequent compared with synthetic drugs, but well-controlled clinical trials have now confirmed that such effects really exist. Several regulatory models for herbal medicines are currently available including prescription drugs, over-the-counter substances, traditional medicines and dietary supplements. Harmonization and improvement in the processes of regulation is needed, and the general tendency is to perpetuate the German Commission E experience, which combines scientific studies and traditional knowledge (monographs). Finally, the trend in the domestication, production and biotechnological studies and genetic improvement of medicinal plants, instead of the use of plants harvested in the wild, will offer great advantages, since it will be possible to obtain uniform and high quality raw materials which are fundamental to the efficacy and safety of herbal drugs.

\section{Key words}

- Herbal medicine

- Efficacy

- Safety

- Quality control

- Market

- Regulatory guidelines 


\section{Introduction}

Herbal drugs have been used since ancient times as medicines for the treatment of a range of diseases. Medicinal plants have played a key role in world health. In spite of the great advances observed in modern medicine in recent decades, plants still make an important contribution to health care. Medicinal plants are distributed worldwide, but they are most abundant in tropical countries. Over the past decade, interest in drugs derived from higher plants, especially the phytotherapeutic ones, has increased expressively. It is estimated that about $25 \%$ of all modern medicines are directly or indirectly derived from higher plants (1-4). In some particular cases, such as antitumoral and antimicrobial drugs, about $60 \%$ of the medicines currently available on the market and most of those in the late stages of clinical trials are derived from natural products, mainly from higher plants (3).

According to the World Health Organization (WHO) (5), because of poverty and lack of access to modern medicine, about $65-80 \%$ of the world's population which lives in developing countries depends essentially on plants for primary health care. Currently, the major pharmaceutical companies have demonstrated renewed interest in investigating higher plants as sources for new lead structures and also for the development of standardized phytotherapeutic agents with proved efficacy, safety and quality (2,6-9). Herbal medicinal preparations are normally very popular in developing countries with a long tradition in the use of medicinal plants and also in some developed countries such as Germany, France, Italy and the United States where appropriate guidelines for registration of such medicines exist (715).

This review highlights the current advances in knowledge about the safety, efficacy, quality assurance, marketing and regulatory aspects of botanical medicines.

\section{Definition and main characteristics of herbal medicines (phytotherapeutic agents)}

Phytotherapeutic agents or phytomedicines are standardized herbal preparations consisting of complex mixtures of one or more plants which are used in most countries for the management of various diseases. According to the WHO definition $(5,16,17)$, herbal drugs contain as active ingredients plant parts or plant materials in the crude or processed state plus certain excipients, i.e., solvents, diluents or preservatives. Usually, the active principles responsible for their pharmacological action are unknown. One basic characteristic of phytotherapeutic agents is the fact that they normally do not possess an immediate or strong pharmacological action. For this reason, phytotherapeutic agents are not used for emergency treatment. Other characteristics of herbal medicines are their wide therapeutic use and great acceptance by the population. In contrast to modern medicines, herbal medicines are frequently used to treat chronic diseases. Combinations with chemically defined active substances or isolated constituents are not considered to be herbal medicines. It is important to note that, although homeopathic preparations may frequently contain plants, they are also not considered to be herbal medicines.

Conditions for which consumers use phytomedicines in Germany, a country where herbal drugs are widely used, include: common cold (66\%), flu (38\%), digestive and/or intestinal diseases $(25 \%)$, headache $(25 \%)$, insomnia (25\%), stomach ulcer (34\%), nervousness $(21 \%)$, circulatory disorders $(15 \%)$, bronchitis (15\%), skin diseases $(15 \%)$, and fatigue and exhaustion (12\%). However, so far, relatively few herbal drugs have been evaluated scientifically to prove their safety, potential benefits and effectiveness. The sources of raw material and the good practices of manufacturing processes are certainly the essential steps for the quality con- 
trol of herbal medicines (reviewed in 2,14, 15,18).

Phytotherapeutic agents are normally marketed as standardized preparations in the form of liquid, solid (powdered extract), or viscous preparations. They are prepared by maceration, percolation or distillation (volatile oils). Ethanol, water, or mixtures of ethanol and water are used for the production of fluid extracts. Solid or powered extracts are prepared by evaporation of the solvents used in the process of extraction of the raw material. Some phytotherapeutic agents are greatly concentrated in order to improve their therapeutic efficacy. The standardized powder extract of Ginkgo biloba (50:1), for instance, means that 50 parts of raw material were processed to yield 1 part of standardized powder extract. In this process, it is also possible to remove, when necessary, some secondary metabolites present in the plants which may produce undesirable side effects (reviewed in19).

Compared with well-defined synthetic drugs, herbal medicines exhibit some marked differences, namely:

- the active principles are frequently unknown;

- standardization, stability and quality control are feasible but not easy;

- the availability and quality of raw materials are frequently problematic;

- well-controlled double-blind clinical and toxicological studies to prove their efficacy and safety are rare;

- empirical use in folk medicine is a very important characteristic;

- they have a wide range of therapeutic use and are suitable for chronic treatments;

- the occurrence of undesirable side effects seems to be less frequent with herbal medicines, but well-controlled randomized clinical trials have revealed that they also exist;

- they usually cost less than synthetic drugs.

\section{The worldwide herbal medicine market and the main causes for the increased interest in herbal medicines}

During the past decades, public interest in natural therapies, namely herbal medicine, has increased dramatically not only in developing countries but mainly in industrialized countries (reviewed in 2,8,9,13-15). This has increased the international trade in herbal medicine enormously and has attracted most of the pharmaceutical companies, including the multinationals. Until a few years ago, only small companies had interest in the marketing of herbal medicines. Currently, most large multinational companies are interested in commercializing herbal drugs. It is estimated that the European market alone reached about $\$ 7$ billion in 1997. The German market corresponds to about $50 \%$ of the European market, about $\$ 3.5$ billion which represents about $\$ 42.90$ per capita. This market is followed by France, $\$ 1.8$ billion; Italy, $\$ 700$ million; the United Kingdom, $\$ 400$ million; Spain, $\$ 300$ million; the Netherlands, about $\$ 100$ million. European herbal medicines are distributed under 6 basic therapeutic categories: cardiovascular, $27.0 \%$; respiratory, $15.3 \%$; digestive, $14.4 \%$; tonic, $14.4 \%$; hypnotic/sedative, $9.3 \%$; topical, $7.4 \%$; others, $12.0 \%$.

The herbal medical database (13) indicates that the herbal medicine markets in Asia and Japan reach $\$ 2.3$ and 2.1 billion, respectively. However, in no other country has the herbal medicine marketplace grown more than it has in the in USA. A few years ago, this was a non-existent category of medicine. The US herbal medicine market reached about $\$ 3.2$ billion in 1996, and is expected to reach $\$ 5$ billion in $1999(8,9,14,15)$. According to a national survey, about 60 million Americans over 18 years of age use herbal drugs to treat colds, burns, headaches, allergies, rashes, depression, diarrhea and menopause, among others. Each American 
spends about $\$ 54$ a year buying these medicines. Currently, most medicinal herbs, such as Aloe vera, Panax quinquefolius (American ginseng), Echinacea, Alium sativum, Ginkgo biloba, Serenoa repens (saw palmetto), Valeriana officinalis, etc., are cultivated in the USA and exported to Europe and the Orient. As a natural consequence, many large companies have introduced a line of herbal products into their sales $(8,9,14,15)$.

According to Grünwald (13), the phytomedicine market has grown at an expressive rate worldwide since 1985 (from 5 to $18 \%$ a year). Several important factors have contributed to the growth of this worldwide phytotherapeutic market, among which the following may be mentioned:

- preference of consumers for natural therapies;

- concern regarding undesirable side effects of modern medicines and the belief that herbal drugs are free from side effects, since millions of people all over the world have been using herbal medicines for thousands of years;

- great interest in alternative medicines;

- preference of populations for preventive medicine due to increasing population age;

- the belief that herbal medicines might be of effective benefit in the treatment of certain diseases where conventional therapies and medicines have proven to be inadequate;

- tendency towards self-medication;

- improvement in quality, proof of efficacy and safety of herbal medicines;

- high cost of synthetic medicines.

\section{Evaluation of the efficacy and safety of herbal medicines. The existence of controlled clinical trials}

Depending on the particular country and existing legislation, herbal products used for diagnosis, cure, mitigation, treatment, or prevention of diseases are normally regulated as drugs. However, in some countries, including the United States, botanical products are marketed as "dietary supplement". Other countries treat the herbal preparations as drugs, and to be registered these products need to be tested to prove their safety and clinical efficacy. However, so far, few programs have been established to study the safety and efficacy of herbal medicines as originally proposed by the WHO Guidelines for the assessment of herbal medicines (reviewed in 5,15,16,18,20-22).

Although clinical trials with herbal drugs are feasible, a survey of the specialized literature reveals that few well-controlled double-blind (placebo-controlled) trials have been carried out with herbal medicines. Recent meta-analysis of reviews published in important medical journals, such as the Annals of Internal Medicine, the Journal of the American Medical Association (JAMA), the British Medical Journal, the Lancet, and the British Journal of Clinical Pharmacology, among others, confirms this assumption. Several factors might contribute to the explanation of such discrepancies, for example:

- lack of standardization and quality control of the herbal drugs used in clinical trials;

- use of different dosages of herbal medicines;

- inadequate randomization in most studies, and patients not properly selected;

- numbers of patients in most trials insufficient for the attainment of statistical significance;

- difficulties in establishing appropriate placebos because of the tastes, aromas, etc;

- wide variations in the duration of treatments using herbal medicines.

As a function of such difficulties, few herbal drugs have been studied adequately and well-controlled double-blind clinical trials to prove their safety and efficacy have been lacking. However, a large number of clinical trials have been performed with some herbal drugs, including the extract of Ginkgo biloba (used for the treatment of CNS and 
cardiovascular disorders) (23-25) and $H y$ pericum perforatum (St. John's wort, used as an antidepressant) (26-32). It is important to emphasize that most such clinical studies have received the same criticisms as those mentioned above. Although the clinical trials have shown that these two herbal drugs are quite safe and devoid of serious side effects, their clinical efficacy still requires well-controlled randomized double-blind studies. Other botanical drugs such as Panax ginseng (ginseng) herbs used as a tonic, Tanacetun parthenium (feverfew) used to treat migraine headache, Allium sativum (garlic) used to lower low-density protein cholesterol and some cardiovascular disturbances, Matricaria chamomilla (chamomile) recommended as a carminative, anti-inflammatory and antispasmodic, Silybium marianun (milk thistle) used for repairing liver function including cirrhosis, Valeriana officinalis (valerian), used as a sedative and sleeping aid, Piper methysticum (Kava kava) used as an anxiolytic, Aesculus hippocastanum (horse chestnut) used for the treatment of chronic venous insufficiency, Cassia acutfolia (Senna) and Rhamnus purshiana (cascara sagrada) which are used as laxatives, Echinacea purpura (Echinacea) used as an anti-inflammatory and immunostimulant, Arnica montana (arnica) used to treat post-traumatic and postoperative conditions, and Serenoa repens (saw palmetto) used for the treatment of benign prostatic hyperplasia are all herbal medicines with the largest worldwide market, and although they have been evaluated in different clinical trials, additional well-controlled and appropriate randomized clinical trials are still needed in order to prove their efficacy (33-48).

However, in my opinion the situation will change very quickly because the increase in the world market for medicinal herbs has attracted most of the largest pharmaceutical companies, including some multinationals, and some of them have recently acquired small companies specialized in phy- totherapeutic agents $(8,9,13)$. Since they have accumulated experience and possess expertise in drug development, and mainly because they have the money to carry out the clinical trials, great progress in herbal medicine should occur in the near future.

The general idea that herbal drugs are very safe and free from side effects is false. Plants have hundreds of constituents and some are very toxic such as the most cytotoxic anti-cancer plant-derived drugs, digitalis, the pyrrolizidine alkaloids, ephedrine, phorbol esters, etc. However, the adverse effects of most herbal drugs are relatively less frequent when the drugs are used properly compared with synthetic drugs, but wellcontrolled clinical trials now confirm that they really exist (see references 49-55). Two kinds of side effects have been reported for herbal medicines. The first, considered to be intrinsic to herbal drugs themselves, is mainly related to predictable toxicity, over-dosage and interaction with conventional drugs, as reported for modern medicines. Thus, many cases of allergic reactions have been reported for herbal drugs. On the other hand, most of the known side effects reported for herbal drugs are extrinsic to the preparation and are related to several manufacturing problems such as misidentification of plants, lack of standardization, failure of good manufacturing practice, contamination, substitution and adulteration of plants, incorrect preparations and/or dosage, etc.

Since 1978, more than 4000 herbal medicines have been submitted to pharmacovigilance in Germany and most herbal drugs have been withdrawn from the market because of important toxic effects and risks for human use (18). Among these, we may mention the plants which contain pyrrolizidinic alkaloids, aristolochic acid, berberine, or curcubitacins.

\section{Standardization of botanical herbs and quality of botanical preparations}

Plants contain several hundred constitu- 
ents and some of them are present at very low concentrations. In spite of the modern chemical analytical procedures available, only rarely do phytochemical investigations succeed in isolating and characterizing all secondary metabolites present in the plant extract. Apart from this, plant constituents vary considerably depending on several factors (see below) that impair the quality control of phytotherapeutic agents. Quality control and standardization of herbal medicines involve several steps. However, the source and quality of raw materials play a pivotal role in guaranteeing the quality and stability of herbal preparations. Other factors such as the use of fresh plants, temperature, light exposure, water availability, nutrients, period and time of collection, method of collecting, drying, packing, storage and transportation of raw material, age and part of the plant collected, etc., can greatly affect the quality and consequently the therapeutic value of herbal medicines. Some plant constituents are heat labile and the plants containing them need to be dried at low temperatures. Also, other active principles are destroyed by enzymatic processes that continue for long periods of time after plant collection. This explains why frequently the composition of herbally based drugs is quite variable. Thus, proper standardization and quality control of raw material and the herbal preparations themselves should be permanently carried out. In the cases where the active principles are unknown, marker substance(s) should be established for analytical purposes. However, in most cases these markers have never been tested to see whether they really account for the therapeutic action reported for the herbal drugs. As pointed out before, apart from these variable factors, others such as the method of extraction and contamination with microorganisms, heavy metals, pesticides, etc., can also interfere with the quality, safety and efficacy of herbal drugs. For these reasons, pharmaceutical companies prefer using cultivated plants instead of wild-harvested plants because they show smaller variation in their constituents. Furthermore and certainly more relevant, when medicinal plants are produced by cultivation, the main secondary metabolites can be monitored and this permits definition of the best period for harvesting (reviewed in 15,22,34,56,57).

The recent advances which occurred in the processes of purification, isolation and structure elucidation of naturally occurring substances have made it possible to establish appropriate strategies for the analysis of quality and the process of standardization of herbal preparations in order to maintain as much as possible the homogeneity of the plant extract. Among others, thin-layer chromatography, gas chromatography, high-performance liquid chromatography, mass spectrometry, infrared-spectrometry, ultraviolet/ visible spectrometry, etc., used alone or in combination, can be successfully used for standardization and to control the quality of both the raw material and the finished herbal drugs.

\section{Regulatory aspects and approval of herbal drugs}

The legal process of regulation and legislation of herbal medicines changes from country to country. The reason for this involves mainly cultural aspects and also the fact that herbal medicines are rarely studied scientifically. Thus, few herbal preparations have been tested for safety and efficacy. The WHO has published guidelines in order to define basic criteria for evaluating the quality, safety, and efficacy of herbal medicines aimed at assisting national regulatory authorities, scientific organizations and manufacturers in this particular area (5). Furthermore, the WHO has prepared pharmacopeic monographs on herbal medicines and the basis of guidelines for the assessment of herbal drugs $(16,17)$.

Several regulatory models for herbal medicines currently exist, including prescrip- 
tion drugs, over-the-counter drugs, traditional medicines and dietary supplements. Thus, the need to establish global and/or regional regulatory mechanisms for regulating herbal drugs seems obvious (reviewed in 5,16$18,20-22,58)$. A summary of the regulatory processes related to herbal drugs in some selected countries is presented below.

\section{Argentina}

The Herboristerias are authorized for sale as plant drugs but not as mixtures. Mixtures of plant drugs are controlled (Law No. 16.463). In 1993, a Ministry of Health regulation determined the obligatory registration of medicinal herbs. The Argentinian National Pharmacopea established control over the existence of crude extracts, extracts or fractions of complex chemical composition, and pure active principles. About 889 monographs exist in Argentina. About 56 describe crude drugs alone and 33 describe extracts or fractions.

However, there is lack of control of raw materials, lack of control over the wild plant, lack of scientific criteria for the collection of plants, and lack of control over methods of drying, conservation or grinding.

\section{Australia}

The Australian Parliament established the Working Party on Natural and Nutritional Supplements to review the quality, safety, efficacy and labeling of herbal and related products (Therapeutic Good Act, 1990). The act provides: "that traditional claims for herbal remedies be allowed, providing general advertising requirements are complied with and providing such claims are justified by literature references".

\section{Brazil}

Despite its immense flora, cultural aspect and the widespread use of herbal medicine, so far few efforts have been made in Brazil to establish the quality, safety and efficacy of these products. In 1994, the Ministry of Health created a commission to evaluate the situation of phytotherapeutic agents in Brazil. The commission proposed a directive based mainly on German and French regulations and on WHO guidelines for herbal drugs. In 1995, "Directive Number 6" established the legal requirement for the registration of herbal drugs and defined the phytopharmaceutical product as "a processed drug containing as active ingredients exclusively plant material and/or plant drug preparations. They are intended to treat, cure, alleviate, prevent and diagnose diseases".

The legal requirements for registration of herbal medicines in Brazil demand complete documentation of efficacy, safety and welldefined quality control. For old medicinal herbs already registered, the law established 5 and 10 years for the assessment of their safety and efficacy, respectively. Due to the resistance of some companies, this law has not yet been enforced.

\section{Canada}

In 1986, the Canadian Health Protection Branch (HPB) constituted a special committee (3 pharmacists, 2 herbalists, 1 nutritionist and 1 physician) and classified herbal drugs as "Folk Medicine". The regulation is based on traditional uses, as long as the claim is validated by scientific studies. In 1990, the HPB listed 64 herbs that were considered to be unsafe. In 1992, the HPB submitted a regulatory proposal to the Canadian Parliament and listed another 64 herbs that were considered to be adulterants. The Canadian regulatory system is consistent with $\mathrm{WHO}$ guidelines for the assessment of herbal medicines.

\section{Chile}

In 1992, the Unidad de Medicina Tradicional was established with the objective of in- 
corporating traditional medicine with proven efficacy into health programs (Law No. 19.253, October 1993). Directive No. 435/81 defined herbal drugs with therapeutic indication claims and/or dosage recommendations as being drugs, restricted for sale in pharmacies and drugstores. Registration for marketing authorization is needed for herbal products.

Natural products are legally differentiated as follows: 1) drugs intended to cure, alleviate or prevent disease; 2) food products for medicinal use and with therapeutic properties, and 3) food products for nutritional purposes.

\section{France}

Approximately 200 herbs are approved as OTC in France with varying claims. Licensing approval for phytomedicines is subject to regulations generally required for all drugs. There is only one type of license, but for some plant drugs and preparations, this license is granted on the basis of an adapted documentation and an abridged application. In 1990, 115 herbs plus 31 laxatives were involved in this approval procedure. Currently, about 205 herbal drugs are listed.

\section{Germany}

Germany's Commission E (phytotherapy and herbal substances) was established in 1978. It is an independent division of the German Federal Health Agency that collects information on herbal medicines and evaluates them for safety and efficacy. The following methods and criteria are followed by Commission E: 1) traditional use; 2) chemical data; 3) experimental, pharmacological and toxicological studies; 4) clinical studies; 5) field and epidemiological studies; 6) patient case records submitted from physician's files, and 7) additional studies, including unpublished proprietary data submitted by manufacturers. Two kinds of monographs are prepared: monopreparations and fixed combinations.

The composition of Commission $\mathrm{E}$ is as follows: physicians, pharmacists, pharmacologists, toxicologists, industry representatives and laypersons, for a total of 24 members. Three possibilities for marketing herbal drugs exist: 1) temporary marking authorization for old herbal drugs until they are evaluated for safety and efficacy; 2) monographs of standardized marketing authorization, and 3) individual marketing authorization. Evaluations are published in the form of monographs that approve or disapprove the herbal drugs for over-the-counter use. Herbal medicines are sold in pharmacies, drugstores and health food stores. Some herbal medicines are controlled by a physician's prescription.

Commission $\mathrm{E}$ has published about 300 monographs: 200 "positives" and 100 "negatives". About 600-700 plants are sold in Germany. Approximately $70 \%$ of physicians prescribe registered herbal drugs. Part of annual sales is paid for by government health insurance.

\section{United States of America}

Since 1994, herbal medicines have been regulated under the "Dietary Supplement Health and Education Act of 1994". On the basis of this law, herbal medicines are not evaluated by the Food and Drug Administration and, most important, these products are not intended to diagnose, treat, cure, or prevent diseases. The US government has established the "Office of Alternative Medicine" at the National Institutes of Health (NIH) with the following aims: 1 ) to explore the potential role of dietary supplements in the improvement of health; 2) to promote the scientific study of supplements for maintaining health and preventing chronic diseases; 3) to compile a database of scientific research related to supplements; 4) to coordinate NIH funding for dietary supplements related to the treatment of chronic disease.

\section{Conclusions and future directions}

A search of the literature shows that over 
the last 15 years a great growth and worldwide interest in herbal medicines has taken place, both in developed and developing countries. The growth of the botanical market has attracted much interest on the part of the pharmaceutical companies, which has in turn stimulated the appearance of pre-clinical pharmacological studies and of wellcontrolled and randomized clinical trials to prove their safety and efficacy. The most important scientific journals have dedicated significant efforts to publishing both basic and clinical scientific studies on herbal medicines, and thus certainly will create the scientific basis for the physician's prescription of the herbal drugs. In spite of this, so far insufficient data exist to provide an accurate assessment of the quality, efficacy and safety of most herbal medicines. In my view, it is too early to predict the future of herbal drugs. However, the herbal drug market will certainly continue growing at elevated rates in the first years of the next millennium, but special attention needs to be paid to the following aspects:

- Emphasis on well-controlled and randomized clinical trials to prove the safety and efficacy of herbal medicines. The widespread interest in phytotherapeutic agents over the last decade has attracted the attention of the most important pharmaceutical companies, and most certainly the quality control, efficacy and safety of herbal drugs will be greatly improved in the near future. However, these trials need to be conducted in such a way as to take into account the international guidelines that define such studies. As has occurred recently in some countries, standardized phytotherapeutic agents of proved quality, efficacy and safety will certainly be increasingly prescribed by physicians and dispensed by pharmacists, and perhaps they will be subsidized by health insurance systems in most countries.

- An improvement in the processes of regulation and a global harmonization will be desirable and certainly necessary, and the general tendency is to utilize the German Commission E experience which combines scientific data and traditional knowledge (monographs). Several regulatory models for herbal medicines currently exist, including prescription drugs, overthe-counter substances, traditional medicines and dietary supplements. Thus, the need to establish global and/or regional regulatory mechanisms for regulating herbal drugs seems obvious.

- Emphasis has been placed on domestication, production and biotechnological studies and genetic improvement of medicinal plants. The trend towards the domestication and planting of medicinal plants instead of the use of wild harvested plants will offer great advantages, since it is possible to provide uniform and high quality raw material. As mentioned before, the uniform quality of raw material is the first pivotal step in the process of developing good quality herbal drugs, avoiding misidentification, adulteration, contamination, etc. An important advantage of the process of domestication is the real and important possibility of improving the quality of raw materials through genetic selection and breeding and the development of medicinal plants resistant to microorganism-induced diseases, free of undesirable secondary metabolites, or rich in bioactive constituents.

- Finally, but not less important, a more detailed legislation about the intellectual property of herbal drugs is urgently needed. The concern and difficulties related to the patenting of herbal medicines have precluded the financial incentives that could be provided to pharmaceutical industries.

\section{Ackowledgments}

The author wishes to thank Patrícia V. de Abreu for assistance in the preparation of this manuscript. 


\section{References}

1. Farnsworth NR \& Morris RW (1976). Higher plants - the sleeping giant of drug development. American J ournal of Pharmaceutical Education, 148: 46-52.

2. De Smet PAGM (1997). The role of plantderived drugs and herbal medicines in healthcare. Drugs, 54: 801-840.

3. Cragg GM, Newman DJ \& Snader KM (1997). Natural products in drug discovery and development. J ournal of Natural Products, 60: 52-60.

4. Shu YZ (1998). Recent natural products based drug development: A pharmaceutical industry perspective. J ournal of Natural Products, 61: 1053-1071.

5. Akerele O (1993). Summary of WHO guidelines for the assessment of herbal medicines. HerbalGram, 28: 13-19.

6. Editorial (1994). Pharmaceuticals from plants: great potential, few funds. Lancet, 343: 1513-1515.

7. Brevoort P (1995). The U.S. botanical market. An overview. HerbalGram, 36: 49-59.

8. Blumenthal M (1999). Harvard study estimates consumers spend $\$ 5.1$ billion on herbal products? HerbalGram, 45: 68.

9. Blumenthal M (1999). Herb industry sees mergers, acquisitions, and entry by pharmaceutical giants in 1998. HerbalGram, 45: 67-68.

10. Brevoort P (1996). Botanical (herbal) medicine in the United States. Pharmaceutical News, 3: 26-28.

11. Eisenberg DM, Kessler RC, Foster C, Norlock FE, Calkins DR \& Delbanco TL (1993). Unconventional medicine in the United States. New England J ournal of Medicine, 328: 246-252.

12. Fisher P \& Ward A (1994). Complementary medicine in Europe. British Medical J ournal, 309: 107-111.

13. Grünwald J (1995). The European phytomedicines market: figures, trends, analysis. HerbalGram, 34: 60-65.

14. Roberts JE \& Tyler VE (1998). Tyler's Herbs of Choice. The Therapeutic Use of Phytomedicinals. The Haworth Press, Inc., New York.

15. Blumenthal M, Brusse WR, Goldberg A, Gruenwald J , Hall T, Riggins CW \& Rister RS (1998). The Complete German Commission E Monographs. Therapeutic Guide to Herbal Medicines. The American Botanical Council, Austin, TX, USA.

16. Bulletin of the World Health Organization (1993). Research guidelines for evaluating the safety and efficacy of herbal medicine. Geneva, 1-86.

17. Bulletin of the World Health Organization
(1998). Regulatory situation of herbal medicines. A worldwide review. Geneva, 1-43.

18. Keller K (1996). Herbal medicinal products in Germany and Europe: experiences with national and European assessment. Drug Information J ournal, 30: 933-948.

19. Schulz V, Hänsel R \& Tyler VE (1996). Rational Phytotherapy. A Physicians' Guide to Herbal Medicine. 3rd edn. Springer-Verlag, Berlin.

20. Zeisel SH (1999). Regulation of "nutraceuticals". Science, 285: 1853-1855.

21. Petrovick PR, Marques LC \& Paula IC (1999). New rules for phytopharmaceutical drug registration in Brazil. J oumal of Ethnopharmacology, 66: 51-55.

22. Eskinazi $D$, Blumenthal $M$, Farnsworth $N$ \& Riggins CW (1999). Botanical Medicine: Efficacy, Quality Assurance, and Regulation. Mary Ann Liebert, Inc. Publisher, New York.

23. Brautigam MRH, Blommaert FA, Verleye G, Castermans J , Steur ENHJ \& Kleijnen J (1998). Treatment of age-related memory complaints with Ginkgo biloba extract: a randomized double blind placebo-controlled study. Phytomedicine, 5: 425-434.

24. Kanowski S, Herrmann WM, Stephan K, Wierich W \& Hörr R (1997). Proof of efficacy of the Ginkgo biloba special extract EGb 761 in outpatients suffering from mild to moderate primary degenerative dementia of the Alzheimer type or multiinfarct dementia. Phytomedicine, 4: 3-13.

25. Kleijnen J (1992). Knipschild P Ginkgo biloba. Lancet, 340: 1136-1139.

26. Ernst E, Rand JI \& Stevinson C (1998). Complementary therapies for depression - An overview. Archives of General Psychiatry, 55: 1026-1032.

27. Harrer $G$, Schimidt $U$, Kuhn $U$ \& Biller $A$ (1999). Comparison of equivalent between the St. J ohn's wort extract LoHyp57 and fluoxetine. Arzneimittel-Forschung/Drug Research, 49: 289-296.

28. J osey ES \& Tackett RL (1999). St. J ohn's wort: a new alternative for depression? International J ournal of Clinical Pharmacology and Therapeutics, 37: 111-119.

29. Laakmann G, Schüle C, Baghai T \& Kieser M (1998). St. J ohn's wort in mild to moderate depression: the relevance of hyperforin for the clinical efficacy. Pharmacopsychiatry, 31: 54-59.

30. Linde K, Raminez G, Mulrow CD, Pauls A, Weidenhammer W \& Melchart D (1996). St. J ohn's wort for depression - an overview and meta-analysis of randomized clinical trials. British Medical J ournal, 313: 253-258.

31. Vitiello B (1999). Hypericum perforatum extracts as potential antidepressants. J ournal of Pharmacy and Pharmacology, 51: 513-517.

32. Woelk H, Burkard G \& Grünwald J (1994). Benefits and risks of the Hypericum extract LI 160: drug monitoring study with 3250 patients. Geriatric Psychiatry and Neurology, 7 (Suppl 1): S34-S38.

33. Armstrong NC \& Ernst E (1999). The treatment of eczema with Chinese herbs: a systematic review of randomized clinical trials. British J oumal of Clinical Pharmacology, 48: 262-264.

34. Bauer R \& Tittel G (1996). Quality assessment of herbal preparations as a precondition of pharmacological and clinical studies. Phytomedicine, 2: 193-198.

35. Bell LP, Hectorne K, Reynolds H, Balm TK \& Hunninghake DB (1989). Cholesterollowering effects of psyllium hydrophilic mucilloid. Adjunct therapy to a prudent diet for patients with mild to moderate hypercholesterolemia. J ournal of the American Medical Association, 261: 34193423.

36. Bensoussan A, Talley NJ, Hing $M$, Menzies R, Guo A \& Ngu M (1998). Treatment of irritable bowel syndrome with Chinese herbal medicine: a randomized controlled trial. J ournal of the American Medical Association, 280: 1585-1589.

37. Borchers AT, Hackman RM, Keen CL, Stern J S \& Gershwin ME (1997). Complementary medicine: A review of immunomodulatory effects of Chinese herbal medicines. American J ournal of Clinical Nutrition, 66: 1303-1312

38. Diehm C, Trampisch HJ, Lange $\mathrm{S} \&$ Schmidt C (1996). Comparison of leg compression stocking and oral horse-chestnut seed extract therapy in patients with chronic venous insufficiency. Lancet, 347: 292-294.

39. Fairfield KM, Eisenberg DM, Davis RB, Libman H \& Phillips RS (1998). Patterns of use, expenditures, and perceived efficacy of complementary and alternative therapies in HIV-infected patients. Archives of Internal Medicine, 158: 2257-2264.

40. Grasso M, Montesano A, Buonaguidi A, Castelli M, Lania C, Rigatti P, Rocco F, Cesana BM \& Borghi C (1995). Comparative effects of alfuzosin versus Serenoa repens in the treatment of symptomatic benign prostatic hyperplasia. Archives of Experimental Urology, 48: 97-103. 
41. Högel J \& Gaus W (1995). Studies on the efficacy of unconventional therapies. Arzneimittel-Forschung/Drug Research, 45: 88-92.

42. J ohnson ES, Kadam NP, Hylands DM \& Hylands PJ (1985). Efficacy of feverfew as prophylactic treatment of migraine. British Medical J ournal, 291: 569-573.

43. Masshour $\mathrm{NH}$, Lin $\mathrm{Gl} \&$ Frishman $\mathrm{WH}$ (1998). Herbal medicine for the treatment of cardiovascular disease. Archives of Internal Medicine, 158: 2225-2234.

44. Morris J , Burke V, Mori TA, Vandogen R \& Beilin LJ (1995). Effects of garlic extract on platelet aggregation: a randomized placebo-controlled double-blind study. Clinical and Experimental Pharmacology and Physiology, 22: 414-417.

45. Murphy J J, Heptinstall S \& Mitchell J RA (1988). Randomised double-blind placebocontrolled trial of feverfew in migraine prevention. Lancet, 2: 189-192.

46. Vogler BK, Pittler MH \& Emest E (1998). Feverfew as a preventive treatment for migraine: a systematic review. Cephalal- gia, 18: 704-708.

47. Warshafsky S, Kamer RS \& Sivak SL (1993). Effect of garlic on total serum cholesterol: a meta-analysis. Archives of Internal Medicine, 119: 599-605.

48. Wilt TJ , Ishani A, Stark G, MacDonald R, Lau J \& Mulrow C (1998). Saw palmetto extracts for treatment of benign prostatic hyperplasia: a systematic review. J ournal of the American Medical Association, 280: 1604-1609.

49. Bagheri $H$, Broué $P$, Lacroix $I$, Larrey $D$, Olives J P, Vaysse Ph, Ghisolfi J \& Montastru J L (1998). Fulminant hepatic failure after herbal medicine ingestion in children. Térapie, 53: 77-83.

50. Brinker $F$ (1998). Herb Contraindications and Drug Interactions. 2nd edn. Eclectic Medical Publications, Sandy, OR.

51. Brown RG (1992). Toxicity of Chinese herbal remedies. Lancet, 340: 673.

52. D'Arcy PF (1993). Adverse reactions and interactions with herbal medicines. 2. Drug interactions. Adverse Drug Reactions and Toxicological Reviews, 12: 147-
162.

53. De Smet PAGM (1995). Health risks of herbal remedies. Drug Safety, 13: 81-93.

54. Farnsworth NR (1993). Relative safety of herbal medicines. HerbalGram, 29 (Special Suppl): 36A-36H.

55. Drew A \& Myers SP (1997). Safety issues in herbal medicine: implications for the health professions. Medical J ournal of Australia, 166: 538-541.

56. Lazarowych NJ \& Pekos P (1998). Use of fingerprinting and marker compounds for identification and standardization of botanical drugs: strategies for applying pharmaceutical HPLC analysis to herbal products. Drug Information J ournal, 32: 497512.

57. Li F, Sun S, Wang J \& Wang D (1998). Chromatography of medicinal plants and Chinese traditional medicines. Biomedical Chromatography, 12: 78-85.

58. Foster S \& Tyler VE (1998). Tyler's Honest Herbal. A Sensible Guide to the Use of Herbals and Related Remedies. The Howorth Press, New York. 